\title{
, \\ Avian Pathology \\ Efficacy of an avian colibacillosis live vaccine for layer breeder in Japan
}

\author{
Yusuke UOTANI ${ }^{1)}$, Rie KITAHARA ${ }^{1)}$, Takahiko IMAI ${ }^{1}$, Nobuyuki TSUTSUMI'), \\ Chihiro SASAKAWA ${ }^{1,2)}$, Shinya NAGAI) and Tetsuji NAGANO ${ }^{1) *}$ \\ 1)Nippon Institute for Biological Science, 9-2221-1 Shinmachi, Ome, Tokyo 198-0024, Japan \\ ${ }^{2)}$ Medical Mycology Research Center, Chiba University, 1-8-1 Inohana, Chuo-ku, Chiba 260-8673 Japan
}

J. Vet. Med. Sci.

79(7): 1215-1219, 2017

doi: 10.1292/jvms.17-0189

Received: 10 April 2017

Accepted: 22 May 2017

Published online in J-STAGE:

11 June 2017
ABSTRACT. Colibacillosis is one of an economically significant disease in the poultry industry, especially for meat breed chickens. Recently it has become a serious problem for layer especially when the birds start laying and also at the later stage of laying. In Japan, the productivity of field laying hens improved when the $\Delta c r p$ avian colibacillosis live vaccine ("Gall $N$ tect CBL") was used. The survival rate and egg laying rate increased during almost all of the laying period when compared with the control group. The improvement in productivity was clearly demonstrated by comparing the number of eggs laid per day. The use of an avian colibacillosis live vaccine proved to be cost-effective in laying hens.

KEY WORDS: colibacillosis, Escherichia coli, layer breeder, live vaccine, productivity

It is well-known that avian colibacillosis in broilers not only causes mortality and culling, but also leads to condemnation on inspection and excessive economic losses. The prevalence of avian colibacillosis in layers has rarely been reported until recently when there has been an increased incidence worldwide including in Japan [3, 9, 15, 16, 19-21]. Infection occurs within respiratory organs or the cloaca [9], causing Escherichia coli peritonitis syndrome, salpingitis or internal laying, inducing a lower laying rate or an increased mortality rate $[8,9,20]$. The underlying cause is as yet unknown, but a slightly increased mortality rate has often been reported. The number of died or culled chickens due to colibacillosis increased from around the beginning of egg laying [19], between initiation and the peak of laying [21] or in the later period of laying. The occurrence of avian colibacillosis is easily overlooked as it normally has little impact on hen-day (HD) egg production, except for a case where all of the chickens on a farm were highly infected [1]. However, an analysis of hen-housed $(\mathrm{HH})$ egg production revealed that the economic loss was not small. Adequate ventilation in the chicken house is the best and the drastic measure against colibacillosis but comfortable ventilation conditions depend on many factors and it can be difficult to decide the best settings for temperature and humidity. The use of antibiotics to prevent and treat avian colibacillosis is not much better than careful rearing or vaccination. This is because almost all pathogenic E. coli isolates from layers are resistant to several antibiotics [3,16], and therefore treatment of colibacillosis requires examination of drug sensitivity. In addition, antibiotics should be used carefully so as not to increase multidrug-resistant strains.

Various virulence-associated genes have been studied in recent years as vaccine candidates for avian colibacillosis. The use of recombinant increased serum survival gene (iss) fusion proteins [12], oral vaccination using Salmonella to deliver avian colibacillosis antigens e.g. papA, papG, iutA and $\operatorname{clp} G[2,11]$, deletion of $i b e A$ or pst genes, have all succeeded in reducing virulence [7, 22]. Furthermore, there are many reports of the efficacy of the $\triangle$ aro $A$ vaccine and its potential is widely recognized $[4,5,10,13,17]$. However, deletion of only the $\operatorname{aro} A$ gene is not enough to attenuate the full pathogenicity and deletion of an additional gene such as the $\operatorname{luxS}$ gene is required $[6,18]$.

We have already reported the usefulness of a mutant of $\triangle$ crp of O78 avian pathogenic E. coli [14]. A live vaccine composed of this strain has been marketed since 2012 in Japan. The use of this vaccine will potentially improve the decreased productivity caused by avian colibacillosis in broilers. The precautionary measure of using a live vaccine against avian colibacillosis has gradually become popular for broilers in Japan. We therefore estimated the efficacy of a live vaccine against colibacillosis in layer breeders in Japan.

We used a live vaccine "Gall N tect CBL" (Nisseiken Co., Ltd., Tokyo, Japan) in this study. The vaccine is made up of $10^{7}-10^{9}$ colony-forming-units (CFU)/dose of AESN1331 O78 APEC strain which has a delated crp gene and has been freeze-dried with skim-milk [14]. The trial farm was situated in Kyushu region in Japan and the chicken houses were open-sided with floor-feeding. This farm was often troubled with increasing mortality rate at the later period of laying caused by an avian collibacillosis. The

*Correspondence to: Nagano, T., Nippon Institute for Biological Science, 9-2221-1 Shinmachi, Ome, Tokyo 198-0024, Japan. e-mail: nagano-t@nibs.or.jp

(C2017 The Japanese Society of Veterinary Science

This is an open-access article distributed under the terms of the Creative Commons Attribution Non-Commercial No Derivatives (by-nc-nd) License. (CC-BY-NC-ND 4.0: https://creativecommons.org/licenses/by-nc-nd/4.0/) 


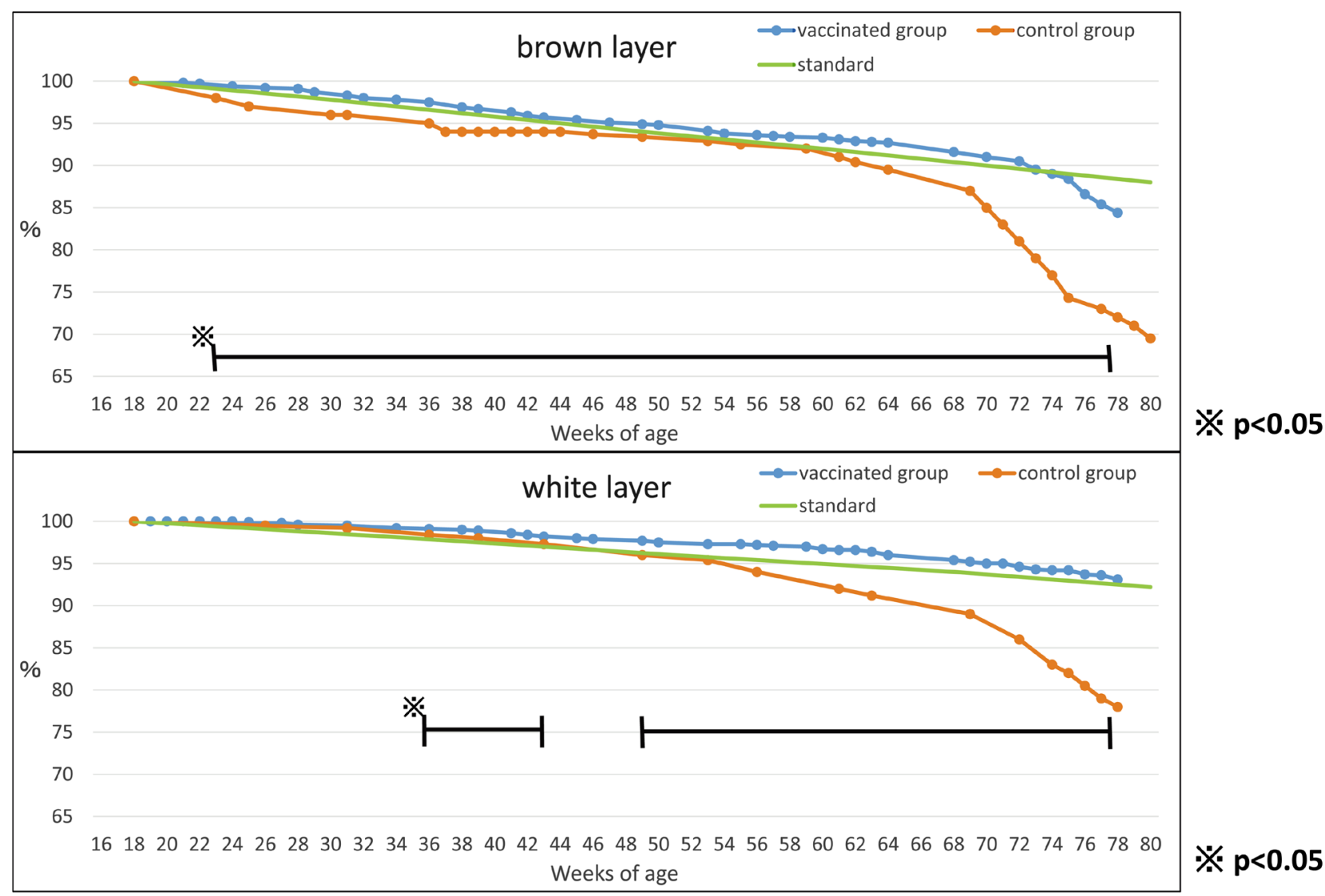

Fig. 1. Survival rates of brown layer and white layer.

layer chicken breeds used in this trial were 8,000 brown layers and 8,000 white layers. The chickens were divided by laying houses so that brown layers were equally divided into vaccinated and non-vaccinated groups, and white layers were divided into 2,000 birds in the vaccinated group and 6,000 birds in the non-vaccinated group. The vaccine was dissolved in sterile saline, and administered at 28 days of age as a fine spray $(0.3 \mathrm{ml} / \mathrm{bird} /$ dose $)$ and again at 64 days of age as a coarse spray $(0.5 \mathrm{~m} / / \mathrm{bird} / \mathrm{dose})$. The fine spray was delivered as droplets of $<100 \mu \mathrm{m}$ using a New-con 607 (Thomas Industries, Louisville, KY, U.S.A.) and the coarse spray was delivered as droplets of $>100 \mu \mathrm{m}$ using a Pana-Spray (Panasonic, Osaka, Japan). After moving from the rearing to the laying house at 120 days of age, survival rate, laying rate, average egg weights and average body weights in the vaccinated group were recorded and compared with those of the non-vaccinated control group. We compared the results with the standards for survival rate and laying rate from the breeding manual (Figs. 1 and 2). For comparison with the brown layer group the HD egg laying number was converted to the equivalent for 4,000 white layers (Fig. 5).

Fisher's exact and $\chi^{2}$ tests were used to compare both survival rate and laying rate. The results for both groups between 65 and 67 weeks of age were deleted because of a breakdown of water-supply equipment at the chicken house containing the vaccinated group.

After the introduction of vaccination, the survival rates of the vaccinated groups were higher than those of the control groups in both breeds (Fig. 1). Furthermore, they were higher than the standard for each breed for almost all of the laying period. The survival rate in the control groups suddenly dropped from the age of 56-60 weeks and older, and was lower than $80 \%$ at age 78 weeks. However, the rates were markedly improved in the vaccinated groups. The egg laying rate of the non-vaccinated group was slightly lower than the standard in both breeds except at the initiation of egg laying. However, rates for both vaccinated groups were higher than the standard, even after the peak of egg production (Fig. 2). Although the rate temporarily decreased due to a problem with the drinking water system at around 65-67 weeks of age, 2 egg laying rates increased again and were higher than the standards for both breeds at 78 weeks. We diagnosed as an avian collibacillosis occurred by dissection, confirming pericarditis and peritonitis when mortality rate was increased. The occurrence of avian colibacillosis increased at the beginning of egg laying and at the peak of laying, when laying hens had become stressed. According to the brown layer breeding manual, the point of 50\% egg laying rate is 143 days old, and the peak laying rate is from 26 to 28 weeks old. For white layer, the point of $50 \%$ egg laying rate is 147 days old, and the peak laying rate is from 33 to 36 weeks old. It was considered that the vaccine could help to prevent infection during these peak stressful periods, so that the initial survival rate and laying rate might be improved. Improvements in egg laying in both breeds were assumed to be a phenomenon secondary to the improved health condition resulting from the control of infection with APEC. There were no differences in the average egg weights between vaccinated and control groups in either 


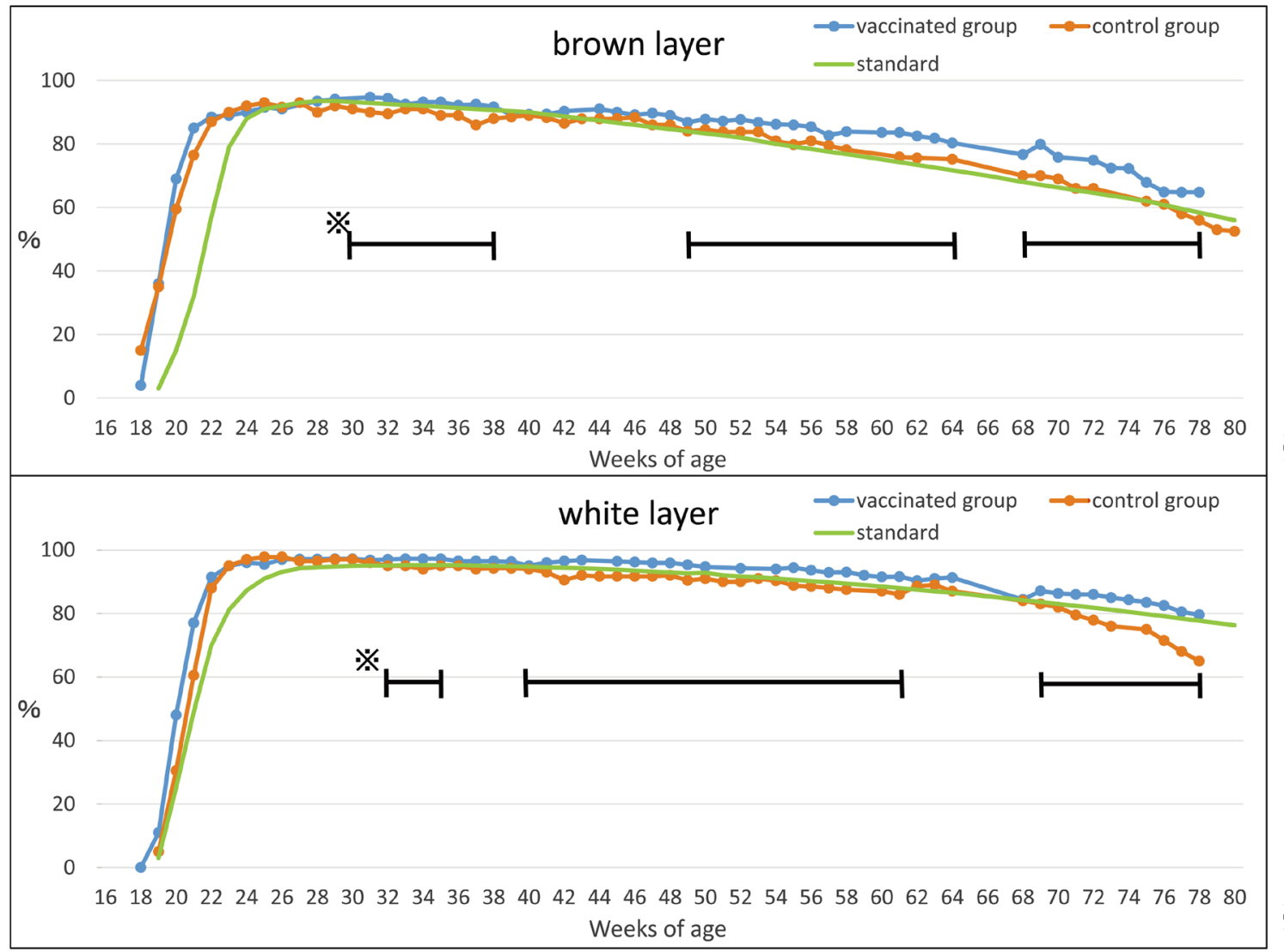

Fig. 2. Egg laying rates of brown layer and white layer.

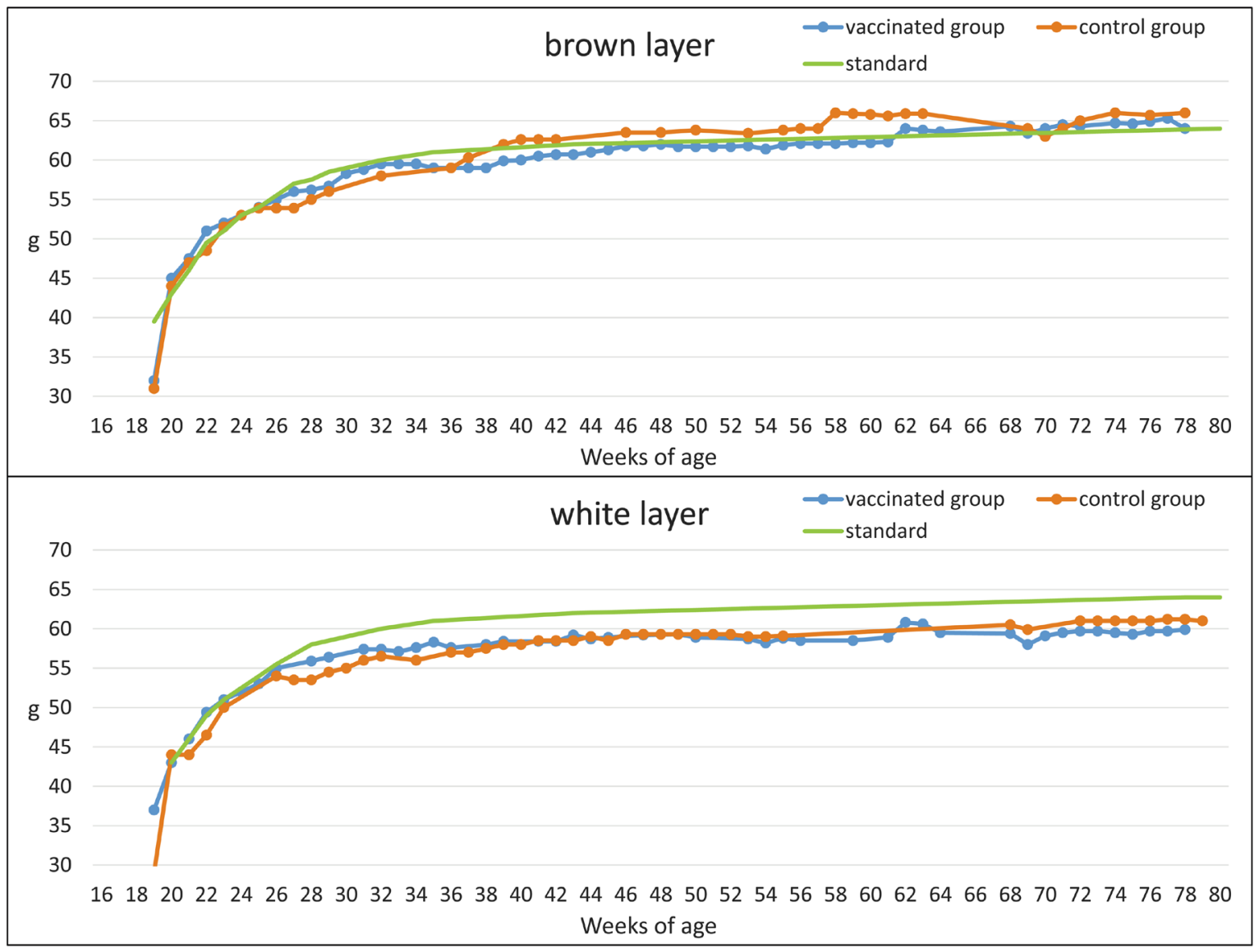

Fig. 3. Average weight of brown layer and white layer eggs. 


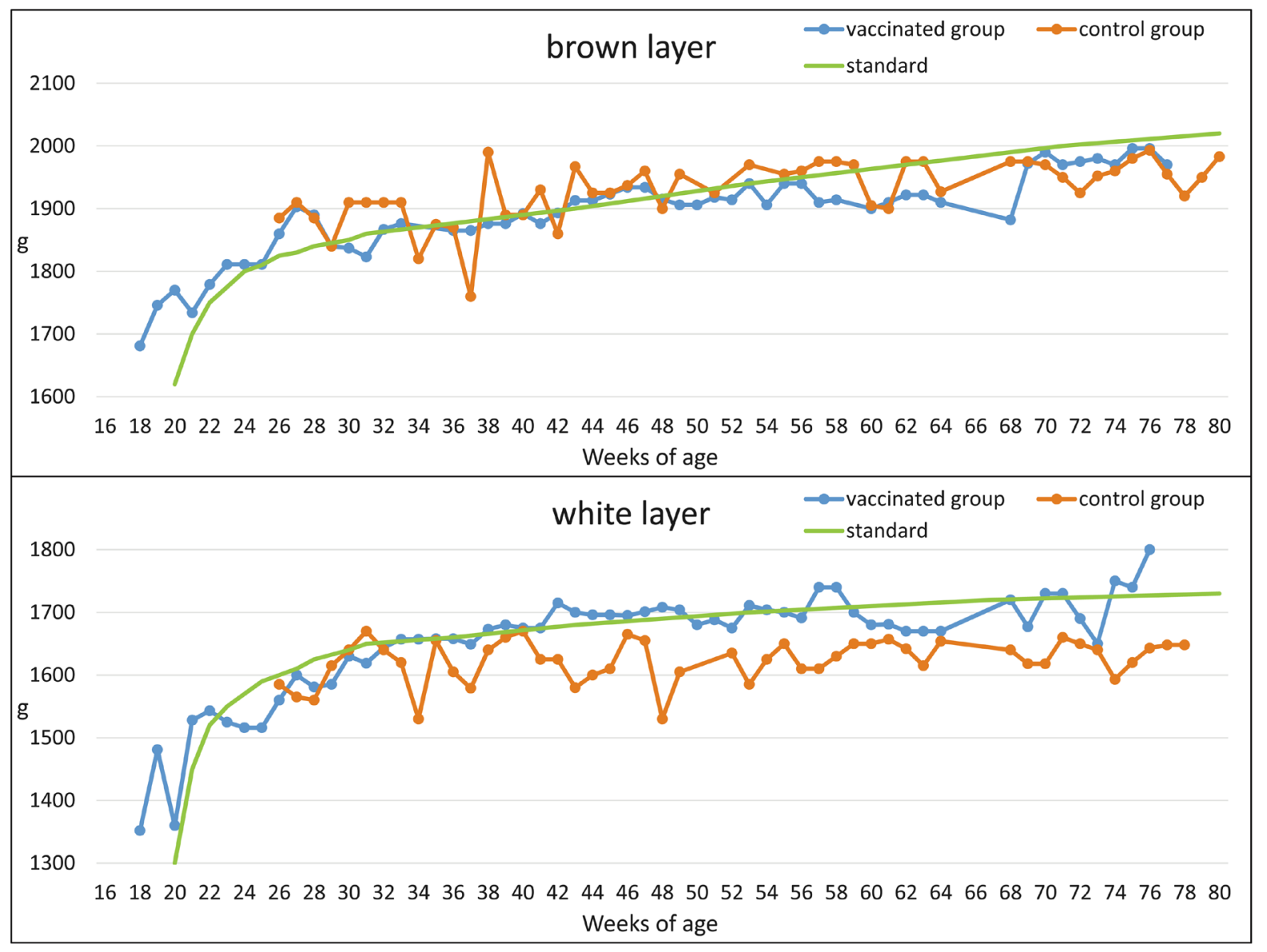

Fig. 4. Average body weights of brown layer and white layer.

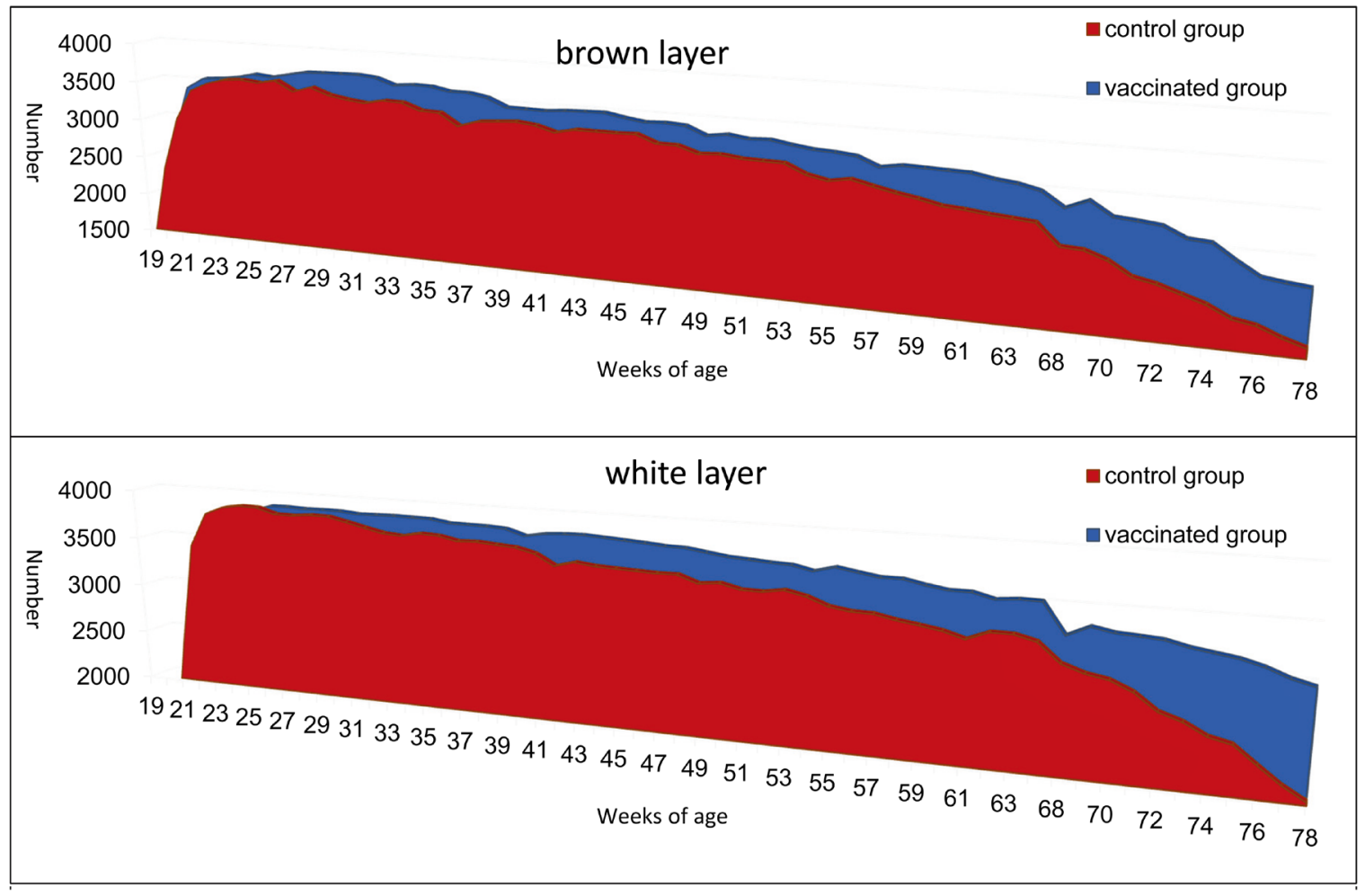

Fig. 5. HD egg laying numbers for brown layer and white layer. 
breed (Fig. 3). Discrepancies between the average body weights for standard and the control groups were wide, compared with those of the vaccinated group in both breeds (Fig. 4). As described above, the improvement in productivity resulting from a largely improved survival rate and high egg laying rate after vaccination was clearly observed by comparing the number of eggs laid per day (Fig. 5). When the increase in the number of eggs was converted into the value per 4,000 hens, the total number of HH eggs increased by 101,470 eggs in brown layer and 108,183 eggs in white layer. The gross margin cannot be simply calculated because the egg price is different between breeds and parent stocks. However, we have convincingly demonstrated that Gall N tect CBL is a cost-effective vaccine.

In summary an avian colibacillosis live vaccine deleting the crp gene is a useful candidate for layer chicken breeds because it prevents avian colibacillosis infection and improves productivity.

\section{REFERENCES}

1. Barnes, H. J., Nolan, L. K. and Vaillancourt, J. P. 2008. Colibacillosis. pp. 691-732. In: Diseases of Poultry, 12th ed. (Saif, Y. M. ed.), Blackwell Publishing, Ames.

2. Chaudhari, A. A., Matsuda, K. and Lee, J. H. 2013. Construction of an attenuated Salmonella delivery system harboring genes encoding various virulence factors of avian pathogenic Escherichia coli and its potential as a candidate vaccine for chicken colibacillosis. Avian Dis. 57: 88-96. [Medline] [CrossRef]

3. Dou, X., Gong, J., Han, X., Xu, M., Shen, H., Zhang, D., Zhuang, L., Liu, J. and Zou, J. 2016. Characterization of avian pathogenic Escherichia coli isolated in eastern China. Gene 576: 244-248. [Medline] [CrossRef]

4. European Medicines Agency (EMA). CVMP assessment report for Poulvac E. Coli. Veterinary Medicines and Product Data Management EMA/ CVMP/298291/2012, London.

5. Fernandes Filho, T., Fávaro, C. Jr., Ingberman, M., Beirão, B. C., Inoue, A., Gomes, L. and Caron, L. F. 2013. Effect of spray Escherichia coli vaccine on the immunity of poultry. Avian Dis. 57: 671-676. [Medline] [CrossRef]

6. Han, X., Bai, H., Tu, J., Yang, L., Xu, D., Wang, S., Qi, K., Fan, G., Zhang, Y., Zuo, J., Tian, M., Ding, C. and Yu, S. 2015. Deletion of luxS further attenuates the virulence of the avian pathogenic Escherichia coli aroA mutant. Microb. Pathog. 88: 39-47. [Medline] [CrossRef]

7. Lamarche, M. G., Dozois, C. M., Daigle, F., Caza, M., Curtiss, R. 3rd., Dubreuil, J. D. and Harel, J. 2005. Inactivation of the pst system reduces the virulence of an avian pathogenic Escherichia coli O78 strain. Infect. Immun. 73: 4138-4145. [Medline] [CrossRef]

8. Landman, W. J. and van Eck, J. H. 2015. The incidence and economic impact of the Escherichia coli peritonitis syndrome in Dutch poultry farming. Avian Pathol. 44: 370-378. [Medline] [CrossRef]

9. Landman, W. J., Heuvelink, A. and van Eck, J. H. 2013. Reproduction of the Escherichia coli peritonitis syndrome in laying hens. Avian Pathol. 42: 157-162. [Medline] [CrossRef]

10. La Ragione, R. M., Woodward, M. J., Kumar, M., Rodenberg, J., Fan, H., Wales, A. D. and Karaca, K. 2013. Efficacy of a live attenuated Escherichia coli O78:K80 vaccine in chickens and turkeys. Avian Dis. 57: 273-279. [Medline] [CrossRef]

11. Lee, J. H., Chaudhari, A. A., Oh, I. G., Eo, S. K., Park, S. Y. and Jawale, C. V. 2015. Immune responses to oral vaccination with Salmonelladelivered avian pathogenic Escherichia coli antigens and protective efficacy against colibacillosis. Can. J. Vet. Res. 79: 229-234. [Medline]

12. Lynne, A. M., Kariyawasam, S., Wannemuehler, Y., Johnson, T. J., Johnson, S. J., Sinha, A. S., Lynne, D. K., Moon, H. W., Jordan, D. M., Logue, C. M., Foley, S. L. and Nolan, L. K. 2012. Recombinant Iss as a potential vaccine for avian colibacillosis. Avian Dis. 56: 192-199. [Medline] [CrossRef]

13. Mombarg, M., Bouzoubaa, K., Andrews, S., Vanimisetti, H. B., Rodenberg, J. and Karaca, K. 2014. Safety and efficacy of an aroA-deleted live vaccine against avian colibacillosis in a multicentre field trial in broilers in Morocco. Avian Pathol. 43: 276-281. [Medline] [CrossRef]

14. Nagano, T., Kitahara, R. and Nagai, S. 2012. An attenuated mutant of avian pathogenic Escherichia coli serovar O78: a possible live vaccine strain for prevention of avian colibacillosis. Microbiol. Immunol. 56: 605-612. [Medline] [CrossRef]

15. Oh, J. Y., Kang, M. S., Kim, J. M., An, B. K., Song, E. A., Kim, J. Y., Shin, E. G., Kim, M. J., Kwon, J. H. and Kwon, Y. K. 2011. Characterization of Escherichia coli isolates from laying hens with colibacillosis on 2 commercial egg-producing farms in Korea. Poult. Sci. 90: $1948-1954$. [Medline] [CrossRef]

16. Oosterik, L. H., Peeters, L., Mutuku, I., Goddeeris, B. M. and Butaye, P. 2014. Susceptibility of avian pathogenic Escherichia coli from laying hens in Belgium to antibiotics and disinfectants and integron prevalence. Avian Dis. 58: 271-278. [Medline] [CrossRef]

17. Sadeyen, J. R., Wu, Z., Davies, H., van Diemen, P. M., Milicic, A., La Ragione, R. M., Kaiser, P., Stevens, M. P. and Dziva, F. 2015. Immune responses associated with homologous protection conferred by commercial vaccines for control of avian pathogenic Escherichia coli in turkeys. Vet. Res. (Faisalabad) 46: 5. [Medline] [CrossRef]

18. Salehi, T. Z., Tabatabaei, S., Karimi, V., Fasaei, B. N., Derakhshandeh, A. and Jahromi, A. O. 2012. Assessment of immunity against avian colibacillosis induced by an aroA mutant containing increased serum survival gene in broilers. Braz. J. Microbiol. 43: 363-370. [Medline] [CrossRef]

19. Someya, A., Otsuki, K. and Murase, T. 2007. Characterization of Escherichia coli strains obtained from layer chickens affected with colibacillosis in a commercial egg-producing farm. J. Vet. Med. Sci. 69: 1009-1014. [Medline] [CrossRef]

20. Srinivasan, P., Balasubramaniam, G. A., Murthy, T. R. and Balachandran, P. 2013. Bacteriological and pathological studies of egg peritonitis in commercial layer chicken in Namakkal area. Asian Pac. J. Trop. Biomed. 3: 988-994. [Medline] [CrossRef]

21. Vandekerchove, D., De Herdt, P., Laevens, H. and Pasmans, F. 2004. Colibacillosis in caged layer hens: characteristics of the disease and the aetiological agent. Avian Pathol. 33: 117-125. [Medline]

22. Wang, S., Niu, C., Shi, Z., Xia, Y., Yaqoob, M., Dai, J. and Lu, C. 2011. Effects of ibeA deletion on virulence and biofilm formation of avian pathogenic Escherichia coli. Infect. Immun. 79: 279-287. [Medline] [CrossRef] 